\title{
Mental and Psychological Well-Being Threats That Meets COVID-19 Patients in ICU and Treatment Options
}

\section{Opinion}

Volume 2 Issue 1- 2021

\author{
Author Details \\ Nahla Shaaban Khalil* \\ Professor at critical care and emergency Nursing Cairo University, Egypt \\ *Corresponding author \\ Nahla Shaaban Khalil, Professor at critical care and emergency Nursing Cairo University, Egypt \\ Article History \\ Received: April 21, 2021 Accepted: April 21, $2021 \quad$ Published: April 22, 2021
}

Keywords: COVID-19 pandemic, Patients' complains, Anxiety, Depression, Digitally communicate

\section{Opinion}

COVID-19 pandemic is stressful for patients and nurses. So, the patients experience physical, mental and psychological problems related to the coronavirus pandemic. such as pain, anxiety, insomnia, depression, loneliness in isolation units, disorientation, psychological distress $[1,2]$. Little interest has been given to common complaints of COVID-19 patients and their families. As well, the fear of acquiring the virus within the hospital may be an additional stressor of patients' families. Moreover, restrictions on family visitors also increase the patients' complains of loneliness, anxiety and depression. These patients need psychological support that cannot be given to them due to their isolation and increased nurses workload with their acute physical care.

Besides, coronavirus patients experience many health problems in ICU settings such as noise induced by equipment (e.g. monitor alarm and mechanical ventilation) and Noise caused by health care providers (e.g.loud voices). So, the critical care nurses and other care provides must make the best use of alarm settings and implement the appropriate measure for reduction of mechanical noises such as wearing of ear plug at night to reduce noise and improve sleeping [3]. Regarding the isolation of coronavirus patients and inability to communicate, the health care providers and authoritative personnel must collaborate together and consider giving the patient with the chance to digitally communicate with their families and friends through paper based or digital media. One of proposed digital media is Video conferences for contacting with their families but its uses have their restrictions [4]. Family support was proven to reduce patients ' anxiety and pain during the care of corona virus patients in ICU settings [5].
Furthermore, due to the very high nurses' workload, it was sometimes necessary to downscale elements of ICU care, including giving a lower attention and priority for screening patients for delirium. Hence, it was unexpected, but nevertheless very important that recently two multicentre studies were published revealing that prevalence of delirium is high in COVID-19 ICU patients between 55-65\% [6,7] and benzodiazepines were administered in $64 \%$ and $78 \%$ [8] of the patients. Compliance with delirium management bundle is essential. Finally, besides physical wellbeing, we have to keep in mind the psychological support, as well as the mental health of corona virus patients and their families.

\section{References}

1. Czeisler MÉ, Lane RI, Petrosky E, Joshua F Wiley, Aleta Christensen ,et al. Mental Health, Substance Use, and Suicidal Ideation During the COVID-19 Pandemic - United States, June 24-30, 2020. MMWR 69(32):1049-1057.

2. Lai J, Ma S, Wang Y, Cai Z, Jianbo Hu, et al. (2020) Factors Associated with Mental Health Outcomes Among Health Care Workers Exposed to Coronavirus Disease 2019. JAMA Netw Open 3(3): e203976.

3. Khalil NS, Khalil NS, El-Bouraei ZM, Moustafa MF, Shehab El-Deen AHA (2019) Effects of Earplugs and Eye Masks on the Onset of Delirium in a Neuro-Critical Care Unit, Egypt. Nurs Health Care Int J 3(4): 000196.

4. Rose L, Nonoyama M, Rezaie S, Ian Fraser (2014) Psychological wellbeing, health related quality of life and memories of intensive care and a specialised weaning centre reported by survivors of prolonged mechanical ventilation. Intensive Crit Care Nurs 30(3):145-151.

5. Liang, Y, Li J, Pan W (2020) Family satisfaction in the intensive care unit The influence of disease severity, care relationship, patient anxiety and patient pain. Intensive \& crit care nurs 63: 102995.

6. Khan SH, Lindroth H, Perkins AJ, Jamil Y, Wang S, et al, (2020) Delirium incidence, duration, and severity in critically Ill patients with Coronavirus disease 2019. Crit Care Explor 2(12): e0290. 
7. Pun BT, Badenes R, Heras La Calle G, Orun OM, Chen W, et al. (2021) Prevalence and risk factors for delirium in critically ill patients with COVID-19 (COVID-D): a multicentre cohort study. Lancet Respir Med 9(3): 239-250.
8. Khan SH, Lindroth H, Perkins AJ, Jamil Y, Wang S, et al, (2020) Delirium incidence, duration, and severity in critically Ill patients with Coronavirus disease 2019. Crit Care Explor 2(12): e0290. 